\title{
RELATO DE EXPERIÊNCIA DE UMA AÇÃO EXTENSIONISTA SOBRE CONTROLE SOCIAL EM SAÚDE NA ESCOLA
}

\author{
José Carlos Ferreira Couto Filho ${ }^{1}$ \\ Ana Carolina Castro Ferreira ${ }^{2}$ \\ Jackson Almeida Tavares Filho ${ }^{2}$ \\ Jessica Almada Nunes ${ }^{2}$ \\ Luma Rossany Soares Costa ${ }^{2}$ \\ Verônica Carla Gonçalves Lima ${ }^{2}$
}

\begin{abstract}
RESUMO
Este artigo trata-se de um relato de experiência sobre um projeto extensionista elaborado durante a vigência do componente curricular Políticas e Serviços de Saúde. As atividades foram realizadas com um grupo de estudantes do segundo ano do Ensino Médio, em um município no interior da Bahia. As ações foram desenvolvidas através de duas oficinas educativas. O emprego de uma abordagem dinâmica do tema Controle Social no SUS permitiu uma melhor aprendizagem dos alunos. Percebeu-se, durante a prática na escola, que as atividades de educação em saúde são possíveis e podem ser simples em sua execução, gerando importante e essencial interesse na população, e assim a empoderando do conhecimento para o exercício da participação popular no processo de decisão da gestão pública na saúde.
\end{abstract}

Palavras-chave: Adolescentes. Controle Social. Educação em Saúde.

\begin{abstract}
This article is an experience report on a extension project developed during the term of the curricular component Policy and Health Services. The activities were carried out with a group of second year High School students in a city in Bahia. The actions were developed through two educational workshops. The use of a dynamic approach to the theme Social Control in SUS allowed a better student learning. It was noticed during practice in school health education activities are possible and can be simple in its execution, generating important and essential interest in the population, and thus empowering knowledge for the exercise of popular participation in the decision process public health management.
\end{abstract}

Keywords: Adolescents. Health education . Social control.

\section{Introdução}

Após a segunda metade da década de oitenta do século passado, o Brasil viveu um momento de democratização, em um contexto de efervescência política, quando as discussões sobre a participação social retornaram ao cenário, objetivando o controle da sociedade civil organizada sobre o Estado. Com isso, o movimento pela Reforma Sanitária, que envolveu diversos segmentos da sociedade, promoveu de forma participativa um embate contra o então modelo assistencial excludente e segmentado, a favor de um sistema de saúde para todos os cidadãos, qualificado e participativo (ROCHA, 2012). Nesse contexto, a participação da sociedade no setor saúde passou por processos de mudança significativa, que resultaram em um sistema de controle social cada vez mais qualificado, deliberativo, independente e representativo. A democratização das políticas de saúde é exemplo de um dos avanços viabilizados pela existência do controle social (BRASIL, 2013).

\footnotetext{
${ }^{1}$ Docente do Centro de Ciências Biológicas e da Saúde da Universidade Federal do Oeste da Bahia (UFOB). Mestre em Enfermagem e Saúde pela Universidade Estadual do Sudoeste da Bahia (UESB). E-mail: jose.couto@ufob.edu.br

${ }^{2}$ Discentes do Curso de Medicina da Universidade Federal do Oeste da Bahia (UFOB).
} 
Com a nova Constituição Brasileira, de 1988, no capítulo da seguridade social, reconhecendo a saúde como um direito do cidadão e um dever do Estado, nasce o Sistema Único de Saúde (SUS), regulado pela Lei $N^{o}$ 8080/1990. Através da Lei No 8.142/1990, mediante uma grande conquista do movimento sanitarista, se estabelece a participação da comunidade na gestão do SUS. O Brasil passa a adotar juridicamente uma nova forma de relacionamento entre Estado e sociedade no âmbito da saúde (ROCHA, 2012).

Desse modo, a democratização buscou a eliminação das formas autoritárias e tradicionais da gestão das políticas sociais e a adoção de práticas com maior clareza das informações e maior participação da sociedade no processo de decisão. A implantação e o funcionamento dos conselhos de saúde, nas três esferas de governo, foi uma das propostas de democratização, sendo legislado que as decisões desses órgãos devem tratar da formulação de estratégias e do controle da execução das políticas de saúde, com pleno acesso aos aspectos voltados para o setor, propondo critérios para a programação, a execução, o acompanhamento, a avaliação e, também, a elaboração e a aprovação do plano de saúde, bem como o estabelecimento de estratégias para a sua execução (SILVA et al., 2007).

Para que esses espaços institucionalizados de participação popular excutem o seu papel, necessário se faz o exercício da democratização da informação em saúde. Nessa perspectiva, um efetivo controle social implica a redistribuição efetiva do poder e do saber, pois, sem informação e capacidade de interpretação da informação, manter legalmente disciplinado o controle social é insuficiente para o seu pleno exercício. Educação popular em saúde é, portanto, um dos instrumentos de fortalecimento do controle social, pois é o controle social que garante a participação dos usuários na organização, funcionalidade e busca pela qualidade dos serviços de saúde no Brasil (BARROSO; SILVA, 2015).

As experiências de educação popular em saúde têm reafirmado o poder deste dispositivo para a articulação dos níveis de atenção e gestão e na formulação de políticas de saúde com corresponsabilidade e comprometimento dos princípios do SUS. Logo, devem ser valorizadas, qualificadas e adotadas nos processos de educação permanente para o controle social e na mobilização em defesa do SUS, por meio de vivências relevantes para os movimentos sociais na defesa de uma sociedade justa, equânime e democrática (CHAVES et al., 2014).

No entanto, o que se nota é que a participação e o controle social não estão efetivados em plenitude. Colabora para isso a falta de informação e a existência de interesses múltiplos para que a população não saiba que possui direitos e que pode exigi-los. O controle social não é do Estado ou da sociedade civil, mas das classes sociais. Por isso é conflitante, pode ser de uma classe ou de outra, pois a sociedade civil enquanto momento do Estado é um espaço de luta de classes pela disputa de poder. É preciso que o controle social aconteça na prática, para que não fique apenas em lei e que a sociedade civil ocupe de modo pleno e efetivo esses diversos espaços de participação social (ROLIM; CRUZ; SAMPAIO, 2013). 
Nesse contexto, Cotta, Cazal e Rodrigues (2009), propuseram um estudo que teve como objetivo dimensionar o nível de informação e conhecimento dos Conselheiros Municipais de Saúde de Viçosa - MG. Em relação a suas atribuições e funções, observou-se que 41,2\% de conselheiros desconheciam o Regimento Interno, o que poderia estar dificultando o exercício de suas competências. A possibilidade de os conselheiros contribuírem para fiscalizar as execuções financeiras e orçamentárias do Fundo de Saúde Municipal se tornava restrita, pois 67,6\% dos entrevistados não sabiam analisar o Relatório de Gestão; 79,4\% dos conselheiros nunca receberam capacitação e 85\% relataram sentir necessidade de ser capacitados para atuar no conselho. O estudo então considerou que a participação e o controle social conferem transparência ao bem público e, partindo do pressuposto que só se pode controlar aquilo que se conhece, é condição necessária a contínua prática de cursos de capacitação para os conselheiros.

Fomentar ações para o desenvolvimento do controle social na saúde é uma ferramenta que a sociedade possui para participar ativamente nas decisões referentes à saúde pública. No entanto, uma parcela considerável da população não possui o conhecimento necessário para exercer este direito. Os cidadãos podem ser participantes tanto nos conselhos de saúde como nas conferências de saúde.

Batalhar por uma saúde digna passa pelo empreendimento popular, que inclui a participação nas instituições democráticas, mas, também, outras ações coletivas de participação. Para que isso ocorra, ainda é imprescindível avançar na consciência social e na organização de estratégias que organizem a participação da população no controle social. Com o avançar da experiência de democracia popular, é possível consolidar a ação coletiva em detrimento do individualismo (MELO; POSSA, 2016).

Entre esses espaços sociais facilitadores desse processo democrático, o ambiente escolar é um terreno propício para essa transformação. Por isso, inserir a educação em saúde no ambiente escolar é uma forma eficiente de empoderamento da comunidade para o controle social, pois a escola é um ambiente de discussão e de disseminação de ideias. Levar um conhecimento mais aprofundado sobre o controle social no SUS para os estudantes poderá causar um impacto positivo na saúde em seu contexto de vida, pois, além da transmissão da informação acerca do direito à participação nas decisões referentes à saúde, será possível promover um pensamento crítico a respeito do tema.

Desse modo, este estudo tem como objetivo relatar a experiência vivenciada por meio de uma ação extensionista sobre uma oficina educativa envolvendo a temática do controle social na saúde para estudantes de Ensino Médio, uma vez que o ambiente escolar torna-se um facilitador da fomentação desse conhecimento acerca da participação popular frente ao controle social.

\section{Metodologia}


Trata-se de um relato de experiência de uma ação extensionista em educação e saúde vivenciada por discentes e docente do curso de Medicina da Universidade Federal do Oeste da Bahia (UFOB), no Município de Barreiras-BA, localizado a $863 \mathrm{~km}$ da capital baiana. Os participantes do estudo foram estudantes do $2^{\circ}$ ano do Ensino Médio de uma escola estadual do Município. As atividades extensionistas se deram por meio de oficina temática concretizada em duas etapas e foram realizadas no ano de 2016, durante a vigência de um componente curricular da grade do curso de Medicina, "Políticas e Serviços de Saúde”. A execução do referido projeto foi desenvolvida em duas etapas consecutivas.

$\mathrm{Na}$ primeira etapa, objetivou-se sensibilizar os participantes sobre o conhecimento acerca da participação popular e controle social no SUS. Desse modo, foram utilizados vídeos institucionais e educativos a respeito do tema trabalhado, intercalando-se, entre eles, explicações dialogadas para facilitar as contribuições acerca do assunto, por parte dos realizadores. Ao final do primeiro dia, foram realizados os agradecimentos e proposta uma atividade a ser elaborada para a segunda etapa da ação.

Já na segunda etapa, foram elaboradas e executadas atividades lúdicas que simulavam um contraste social por parte dos discentes. Desse modo, os participantes realizam duas dramatizações acerca do tema, em cada uma delas um problema de saúde foi evidenciado e proposta uma reflexão. Por fim, os executores da oficina realizaram uma simulação de um Conselho Municipal de Saúde, com a finalidade de vivenciar de forma fictícia uma aproximação da realidade tendo como pauta os problemas evidenciados nas duas dramatizações. No final da atividade extensionista, foi entregue aos estudantes um folder educativo contendo informações sobre o Conselho de Saúde do Município, e sobre a importância do controle social, com o intuito de que essas informações fossem difundidas pelos participantes aos seus familiares, tornando-os disseminadores do conhecimento apreendido na ação empregada.

\section{Resultados e discussão}

Os desafios foram singulares no que se refere à construção do conhecimento acerca da participação popular na gestão do SUS. Entre esses, evidenciou-se na atividade de extensão que existia um desconhecimento da turma em relação ao assunto exposto, como se os temas Controle Social e Conselho de Saúde fossem novidades para eles, bem como conceitos básicos sobre o SUS e os seus princípios. Desse modo, Da Silva, Cançado e Dos Santos (2017) descrevem que diversos são os caminhos que ainda restam para serem trilhados que envolvam a ressignificação da concepção cívica de participação da sociedade, que pode ser incentivada pela própria academia. A academia precisa, contudo, se equipar de um arcabouço teórico mais aprofundado, que sustente as concepções teóricas e conceituais sobre o Controle Social, mediante novas publicações científicas que se aprofundem nas concepções teóricas relativas ao assunto. 
Entretanto, mesmo com a dificuldade de discorrer sobre a temática proposta, os partícipes apresentaram interesse em participar das perguntas iniciais feitas sobre o tema. Desse modo, os executores da ação educativa utilizaram de metodologias didáticas, por meio de uma construção dialógica, que, por sua vez, facilitaram o processo de construção de aprendizagem. O que se notou foi que os participantes consideraram válidos os temas discutidos, principalmente, quando apresentados por meio de vídeos. Nesse contexto, Chaves et al. (2014) diz que as práticas educativas, a partir da educação popular em saúde, têm contribuído para o controle social e a participação popular, quando produz conhecimento na troca de saberes e contribui na discussão, formulação, produção e apresentação de demandas pelo direito à saúde. Ao ser atingido o final do tempo de aula, nem todos os estudantes puderam permanecer em sala. Apesar disso, o remanescente manteve-se em ativa participação até o término das atividades da primeira etapa da ação educativa.

No segundo momento em que foi realizada a oficina, constituiu-se uma percepção de melhora dos participantes acerca da temática, fruto decorrente das abordagens didáticas realizadas no primeiro momento da oficina. Com a proposta intervencionista por meio do lúdico das duas dramatizações, os estudantes foram conduzidos a propor soluções para essas problemáticas, simulando um Conselho Municipal de Saúde, baseados nos conhecimentos prévios acerca do controle social comunicados na primeira etapa.

Assim, Souza et al. (2012) discorre que o Conselho Municipal de Saúde é apresentado como um espaço privilegiado para a efetivação da participação social e, ainda que reconheçam às limitações presentes, os Conselheiros continuam acreditando que por meio do conselho é possível lutar e conseguir benefícios para a saúde da população do referido município. Assim, o Conselho de Saúde é o local em que o sujeito social tem a oportunidade de colaborar de forma ativa nas decisões do sistema de saúde pública, uma conquista que advém da criação do SUS e precisa ser construída a cada dia, contando com a participação voluntária de cada Conselheiro.

Já para Brasil (2013), os conselhos de saúde e as conferências de saúde se constituem, atualmente, nos principais ambientes para o exercício da participação e do controle social na implantação e na implementação das políticas de saúde em todas as esferas de governo. Atuando como mecanismos essencialmente democráticos, por meio deles, a sociedade se organiza para a efetiva proteção da saúde como direito de todos e dever do Estado.

A partir dessas abordagens, foi avaliado o aprendizado do grupo diante do tema apresentado. Assim, foi possível notar que eles rememoravam alguns conceitos e aplicaram durante a simulação, o que foi um resultado muito satisfatório tanto para os aplicadores da ação educativa quanto para os estudantes. Nesse contexto, Barbosa et al. (2016) descreve que a educação para o controle social e o SUS devem estar integradas a uma política que estimule a transmissão de informações, tendo como atores os profissionais dos serviços, universidades, gestores da saúde e comunidade. Assim, a educação 
popular é uma ferramenta aliada na construção do SUS, pois caracteriza-se como um espaço aberto à comunidade, capaz de promover o diálogo, compartilhar experiências e construir um saber coletivo.

É notório compreender que deve ser congregado à democracia participativa um desempenho educativo, de participação em assuntos comunitários e políticos, o que pode contribuir para a criação de cidadãos adequados para sustentar a democracia. Desse modo, é pelo controle social que se propaga a garantia dos direitos promulgados na Constituição de 1988. Assim, Souza et al. (2012) discorre que o controle social é uma maneira pela qual a sociedade civil garante sua participação nas decisões referentes às políticas de saúde. Dessa forma, os cidadãos ampliam sua participação, interferindo no processo de gestão dos recursos necessários à efetivação das ações em saúde.

No que se refere ao desenvolvimento da atividade extensionista, evidenciou-se que ela é uma ferramenta eficaz para a construção de conhecimento, assim como proporciona aproximação da Universidade à sociedade, rompendo com os muros e mediando instrumentos de transformações sociais. Nesse contexto, Siqueira et al. (2017) afirma que a extensão universitária é um método de influência mútua entre a universidade e a comunidade, e, a partir dela, é plausível desenvolver atividades de promoção da saúde.

No entanto, no que se refere a ações extensionista que objetivam uma reflexão sobre o controle social no SUS, faz-se necessário compreender que os desafios ainda são muitos grandes. A questão do comparecimento e da qualidade da participação dos atores sociais no processo decisório ainda é um desafio. As decisões ainda estão a favor dos atores estatais, que expressam, na maior parte das vezes, em função da característica do processo de construção de representações elitistas do Estado, interesses múltiplos da maioria da população e das classes populares (MELO; POSSA, 2016).

Possibilitando, dessa maneira, uma ação concreta e participativa, os cidadãos podem se tornar mais informados sobre o sistema político, modificar as suas representações e ampliar seus horizontes para além de seus interesses pessoais, ou seja, em defesa de um bem público maior, a defesa do SUS.

\section{Conclusão}

O nível de conhecimento a respeito do tema controle social no SUS na sociedade brasileira, inclusive entre os próprios estudantes e trabalhadores dos setores de saúde, tem se apresentado como uma problemática que inviabiliza o pleno exercício da participação popular no processo decisório da gestão pública.

Os resultados obtidos nessa experiência revelam que, apesar do aspecto burocrático do tema, fora do conjunto de interesses ou talvez inacessível à faixa etária dos estudantes envolvidos, foram satisfatórios, sendo possível refletir sobre as causas possíveis que geram baixo acesso a esse conhecimento, como falta de interesse populacional, falta de divulgação governamental, falta de acesso, ou até mesmo o conjunto dessas causas. A partir do primeiro encontro, foi notado um 
desenvolvimento no interesse dos participantes a respeito do tema. Percebeu-se que havia certo desconhecimento dos preceitos do Sistema Único de Saúde (SUS), incluindo-se aí as diretrizes, o funcionamento, a abrangência e os direitos dos usuários. Entretanto, por meio da abordagem utilizad, foi despertado um maior grau de interesse, de modo que excelentes resultados foram obtidos no segundo encontro, os estudantes do Ensino Médio mostraram-se envolvidos na oficina e demonstraram conhecimentos adquiridos a respeito do tema, mostrando-se inclusive aptos a discorrer sobre isso e incentivar outras pessoas, inclusive por meios de comunicação atuais.

A partir disso, pode ser considerado que possivelmente a falta de interesse da população não seja a maior causa do descaso com o controle social da saúde, embora ainda seja relevante nesse aspecto, mas sim a forma com que esse tema chega aos usuários da saúde, ou mesmo como não chega. É preciso e importante, portanto, que aconteçam tanto da parte governamental quanto institucional programas de estratégias de educação em saúde que visem difundir conhecimentos a respeito desse tema para a população. Isso, no entanto, deve acontecer de forma lúdica e de fácil acesso, de modo que atinja todos os grupos sociais, visto que o sistema é universal.

Dessa maneira, pôde-se proporcionar ampliação do conhecimento a esses estudantes de uma escola pública na Região Oeste da Bahia sobre o que é o controle social na saúde, seu funcionamento e como é possível o seu envolvimento ativo no Conselho Municipal da Saúde, e contribuição para a construção de uma sociedade local com melhores condições de vida, através da busca voluntária pela efetividade de seu direito à saúde, facilitando o acesso à percepção de sua participação nos processos coletivos, em busca de melhorias na saúde coletiva. Como integrantes da sociedade, os estudantes são um elo forte da cidadania no contexto onde estão inseridos, geradores de mudanças, detentores do conhecimento que os levem a iniciativas de controle social, tirando-os de uma atitude passiva frente a gestões públicas.

\section{Referências}

BARBOSA, A. M. et al. Fórum permanente de educação popular em saúde: construindo estratégias de diálogos e participação popular. Revista de APS, v. 18, n. 4, 2016.

BARROSO, K. de A.; SILVA, G. S. O controle social na atenção primária e a atuação dos conselhos municipais. Arq. Cienc. Saúde UNIPAR, Umuarama, v. 19, n. 3, p. 213-219, set./dez. 2015.

BRASIL. Ministério da Saúde. Conselho Nacional de Saúde. Para entender o controle social na saúde. Brasília, 2013.

CHAVES, L. et al. Curso "Participação popular, movimentos sociais e direito à saúde": uma experiência de educação popular em Saúde na Bahia a partir do Mobiliza SUS. Interface (Botucatu), Botucatu, v. 18, supl. 2, p. 1507-1512, 2014. Disponível em:

$<$ http://www.scielo.br/scielo.php?script=sci_arttext\&pid=S1414-

32832014000601507\&lng=en\&nrm=iso >. Acesso em: 29 abr. 2016. 
COTTA, R. M. M; CAZAL, M. M; RODRIGUES, J. F. C. Participação, controle social e exercício da cidadania: a (des)informação como obstáculo à atuação dos conselheiros de saúde. Physis, Rio de Janeiro, v. 19, n. 2, p. 419-438, 2009. Disponível em:

<http://www.scielo.br/scielo.php?script=sci_arttext\&pid=S0103-

$73312009000200010 \& \operatorname{lng}=$ pt\&nrm=iso $>$. Acesso em: 05 abr. 2016.

DA SILVA, F. R; CANÇADO, A. C.; DOS SANTOS, J. C. Compreensões acerca do conceito de controle social. Desenvolvimento em Questão, v. 15, n. 41, p. 24-58, 2017.

MELO, R. C.; POSSA, L. B. Democracia no SUS, como estamos? Um debate sobre a participação social a partir da literatura recente. Saúde em Redes, Porto Alegre, v. 2, n. 4, p. 393-408, 2016.

ROCHA, J. S. Y. Manual de saúde pública e saúde coletiva no Brasil. São Paulo: Atheneu, 2012.

ROLIM, Leonardo Barbosa; CRUZ, Rachel de Sá Barreto Luna Callou; SAMPAIO, Karla Jimena Araújo de Jesus. Participação popular e o controle social como diretriz do SUS: uma revisão narrativa. Saúde Debate, Rio de Janeiro, v. 37, n. 96, p. 139-147, mar. 2013. Disponível em: $<$ http://www.scielo.br/scielo.php?script=sci_arttext\&pid=S010311042013000100016\&lng=en\&nrm=iso >. Acesso em: 05 abr. 2016.

SILVA, A. X. et al. A importância estratégica da informação em saúde para o exercício do controle social. Ciênc. Saúde Coletiva, Rio de Janeiro, v. 12, n. 3, p. 683-688, jun. 2007. Disponível em: $<$ http://www.scielo.br/scielo.php?script=sci_arttext\&pid=S141381232007000300018\&lng=pt\&nrm=iso >. Acesso em: 05 abr. 2016.

SIQUEIRA, S. M. C. et al. Atividades extensionistas, promoção da saúde e desenvolvimento sustentável: experiência de um grupo de pesquisa em enfermagem. Esc. Anna Nery, Rio de Janeiro, v. 21, n. 1, 2017. Disponível em: <http://www.scielo.br/scielo.php?script=sci_arttext\&pid=S141481452017000100701\&lng=en\&nrm=iso > . Acesso em: 12 dez. 2017.

SOUZA, T. O. et al. Controle social: um desafio para o conselheiro de saúde. Rev. bras. enferm., Brasília, v. 65, n. 2, p. 215-221, abr. 2012. Disponível em:

$<$ http:/ /www.scielo.br/scielo.php?script=sci_arttext\&pid=S0034-

$71672012000200003 \& \operatorname{lng}=$ pt\&nrm=iso $>$. Acesso em: 12 dez. 2017. 